\title{
The predictive factor for pathological downgrading after prostatectomy in patients with biopsy Gleason score $4+3$ or $4+4$ prostate cancer
}

\author{
YOICHIRO TOHI, IORI MATSUDA, KENGO FUJIWARA, SATOSHI HARADA, AYAKO ITO, MARI YAMASAKI, \\ YASUYUKI MIYAUCHI, YUKI MATSUOKA, TAKUMA KATO, RIKIYA TAOKA, \\ HIROYUKI TSUNEMORI, NOBUFUMI UEDA and MIKIO SUGIMOTO
}

Department of Urology, Faculty of Medicine, Kagawa University, Miki-cho, Kita-gun, Kagawa 761-0793, Japan

Received September 29, 2020; Accepted December 9, 2020

DOI: $10.3892 / \mathrm{mco} .2021 .2218$

\begin{abstract}
The proportion of Gleason pattern (GP) 4 prostate cancers at prostate biopsy has a clinically significant impact on risk stratification for patients with prostate cancer. In pathological diagnosis including GP 4, a biopsy Gleason score (GS) of $3+4$ has a more favorable prognosis than a GS of $4+3$ and $4+4$. However, the discrepancy between biopsy and prostatectomy specimens is well known. The current study investigated the clinical parameters and biopsy specimens associated with pathological downgrading after prostatectomy in biopsies with a GS of $4+3$ or $4+4$ prostate cancer. A total of 302 patients with prostate cancer who underwent robot-assisted radical prostatectomy between August 2013 and May 2019 were retrospectively reviewed. A total of 103 patients had biopsies with GSs of 4+3 and GS 4+4 (unfavorable pathology). The proportion of patients who were downgraded from unfavorable disease to GS $\leq 3+4$ (favorable pathology) in prostatectomy specimens was investigated. Logistic regression analysis was used to explore the association between clinical parameters and downgrading in prostatectomy specimens. A total of 43 patients (41.7\%) were downgraded from biopsy GS to prostatectomy GS. The proportions of downgrade in biopsy GS $4+4$ and $4+3$ were 14.6 and $27.1 \%$, respectively. The percentage of highest GS out of positive biopsy cores and the maximum percentage of cancer involvement within a
\end{abstract}

Correspondence to: Dr Yoichiro Tohi, Department of Urology, Faculty of Medicine, Kagawa University, 1750-1 Ikenobe, Miki-cho, Kita-gun, Kagawa 761-0793, Japan

E-mail: yoto716yotoyoto@gmail.com

Abbreviations: GP, Gleason pattern; GS, Gleason score; RALP, robot-assisted laparoscopic radical prostatectomy; PSA, prostate-specific antigen; ORs, odds ratios; CIs, confidence intervals; $\mathrm{IQR}$, interquartile range

Key words: biopsy, Gleason score, prostate cancer, prostatectomy, downgrading biopsy, Gleason positive core with the highest GS were lower in the downgrade group than in the no downgrade group (45 vs. $66.7 \%, \mathrm{P}=0.025$; 20 vs. $30 \%, \mathrm{P}=0.048$, respectively). When performing multivariate logistic regression analysis, the only significant predictor for downgrade was lower percentage of highest GS cores out of positive biopsy cores (odds ratio, 2.469; 95\% confidence interval, 1.029-5.925 $\mathrm{P}=0.043)$. In conclusion, patients with biopsy GS $4+4$ and $4+3$ often exhibit a downgrade to GS $3+4$ or less in prostatectomy specimens. The lower percentage of highest GS cores out of positive biopsy cores was associated with downgrade.

\section{Introduction}

The clinical impact of the proportion of Gleason pattern (GP) 4 prostate cancers in prostate biopsy is very significant in terms of risk stratification for patients with prostate cancer. Risk stratification varies from low risk to high risk depending on whether GP 4 is adopted. Furthermore, the same intermediate-risk Gleason score (GS) 3+4 and GS 4+3 have very different oncological prognoses $(1,2)$. The National Comprehensive Cancer Network Clinical Practice Guidelines divide the risk between GS 3+4 and GS 4+3 (3). In addition, GS 4+3 and GS 4+4 had a similar oncological prognosis (1). In other words, a wide range of risk is assessed, from favorable intermediate to high risk, based on the percentage of GP4 in the prostate biopsy specimen. In clinical practice, risk classification is used to determine the course of treatment.

Currently, in the diagnosis of prostate cancer, the highest biopsy GS is used to assess risk in order to avoid underestimation in biopsy pathology. There are many reports of differences between prostate biopsy specimens and prostatectomy specimens $(4,5)$. Therefore, adopting the highest biopsy GS could be overestimated while ensuring safety. Upgrading from biopsy GS to prostatectomy GS is often reported as a focus for differences between biopsy specimens and prostatectomy specimens (6-8). On the other hand, there are few reports of downgrading from biopsy GS to prostatectomy GS (9-11). In this context, the downgrade has significant implications in patients with biopsy GP 4, who could be assessed by a wide range of risk. Identifying factors that could contribute 
to downgrading prior to treatment would be of great benefit in clinical practice because patients could be provided with a safer guarantee than expected by biopsy GS.

Therefore, we aimed to investigate the factors of clinical parameters and biopsy specimens associated with downgrading in prostatectomy specimens in patients with biopsy GS $4+3$ or GS $4+4$ prostate cancer.

\section{Materials and methods}

Ethics statements. The current study was approved by the Institutional Review Board of Kagawa University (admission no. 2020-074). The need for informed consent was waived given the retrospective nature of the study, but information of this study was disclosed on the website and opportunities for refusal were guaranteed.

Study design and patient population. We performed a retrospective analysis of 302 patients with prostate cancer who underwent robot-assisted laparoscopic radical prostatectomy (RALP) at local hospital from August 2013 to May 2019. Patients were included in this study if the biopsy highest GS was GS 4+3 and GS 4+4 and RALP was performed. Patients were excluded if there was no evidence of nodal or distant metastases on preoperative imaging, Gleason pattern 5 was present in any biopsy cores, neoadjuvant hormonal therapy was used, prior radiation therapy was performed, the diagnostic prostate-specific antigen (PSA) level was $\geq 20 \mathrm{ng} / \mathrm{ml}$, or cancer was clinical stage $\geq \mathrm{cT} 3$.

Definitions. GS $\leq 3+4$ was defined as favorable pathology, and GS 4+3 and GS 4+4 were defined as unfavorable pathology. Downgrading was defined as unfavorable pathology at biopsy to favorable pathology at radical prostatectomy. If a higher tertiary pattern was present in prostatectomy specimens, it was listed as ' $+\mathrm{T}$ ' in the GS. A tertiary pattern of the same Gleason score was not considered grade classification (e.g., biopsy GS 4+4 to prostatectomy GS 3+4+T was considered a downgrade).

Most of the biopsies (76.8\%) were performed at outside institutions, but all biopsy specimens were reviewed at our institution before RALP.

Data collection and statistical analysis. All data were collected from electronic medical records. In the present study, baseline characteristics (age, PSA level at diagnosis, PSA density, prostate volume, clinical T-stage, biopsy GS, number of biopsy cores, number of positive biopsy cores, percentage of positive cores out of all biopsy cores, percentage of highest GS cores out of positive biopsy cores, and maximum percentage of cancer involvement within a positive core with the highest GS) were collected retrospectively. We divided the patients into two groups: The downgrade group from biopsy GS 4+4 or $4+3$ to $\mathrm{GS} \leq 3+4$ at radical prostatectomy and no downgrade group, and compared baseline characteristics between the two groups, using the chi-square and Fisher exact test for categorical variables, and the Mann-Whitney $U$ test for continuous variables. Logistic regression analyses were performed to assess the prediction of GS downgrading after radical prostatectomy in patients with biopsy GS $4+3$ and GS $4+4$. The results of logistic regression analyses are presented as odds ratios (ORs), 95\% confidence intervals (CIs) and P-values. A P-value $<0.05$ was considered to indicate statistical significance. All statistical analyses were performed using SPSS for Windows (version 25.0; IBM Corp.).

\section{Results}

A total of 122 patients with prostate cancer had the highest biopsy GS 4+3 and GS 4+4. Patients who received neoadjuvant hormonal therapy $(n=6)$ and had a Gleason pattern 5 in any biopsy core $(n=2)$, diagnostic PSA level $\geq 20 \mathrm{ng} / \mathrm{ml} \quad(\mathrm{n}=3)$, clinical T stage $\geq$ cT3 $(n=7)$, and both diagnostic PSA level $\geq 20 \mathrm{ng} / \mathrm{ml}$ and clinical $\mathrm{T}$ stage $\geq \mathrm{cT} 3 \quad(\mathrm{n}=1)$ were excluded. Finally, 103 patients met the inclusion criteria for this study. Table I shows the baseline characteristics of patients. Fifty-two patients $(50.5 \%)$ had biopsy GS $4+3$, and 51 patients $(49.5 \%)$ had biopsy GS 4+4. The median percentage of positive cores out of all biopsy cores was $25 \%$ [interquartile range (IQR), 15-36.6]. The median percentage of highest GS cores out of positive biopsy cores was $30 \%$ (IQR, 10-47.5). The median maximum percentage of cancer involvement within a positive core with the highest GS was 50\% (IQR, 33.3-100). The median follow-up time was 36 months (IQR, 12-54.5).

Table II shows the relationship between biopsy and radical prostatectomy GS. Of note, $41.7 \%$ of the patients were downgraded from biopsy GS to radical prostatectomy GS. In detail, the percentages of downgrade were 14.6 and $27.1 \%$ in biopsy GS 4+4 and biopsy GS 4+3, respectively. Table III shows the association of characteristics downgraded from biopsy GS to radical prostatectomy GS. The percentage of highest GS cores out of positive biopsy cores and the maximum percentage of cancer involvement within a positive core with the highest GS were lower in the downgrade group than in the no downgrade group [ 45 vs. $66.7 \%, \mathrm{P}=0.025 ; 20$ vs. $30 \%, \mathrm{P}=0.048$, respectively]. The PSA level at diagnosis $(6.4 \mathrm{vs} .6 .23 \mathrm{ng} / \mathrm{ml}$, $\mathrm{P}=0.973)$, PSA density ( 0.23 vs. $0.26 \mathrm{ng} / \mathrm{ml} / \mathrm{cc}, \mathrm{P}=0.409)$, clinical T stage $(\mathrm{P}=0.361)$, and percent of positive cores out of all biopsy cores ( 25 vs. $25 \%, \mathrm{P}=0.939)$ were not significantly different between the groups. On multivariate logistic regression analysis, the only significant predictor for downgrade was lower percentage of highest GS cores out of positive biopsy cores (OR: 2.469; 95\% CI 1.029-5.925, $\mathrm{P}=0.043$ ) (Table IV).

\section{Discussion}

We demonstrated that $41 \%$ of patients with biopsy GS $4+4$ or GS $4+3$ were downgraded to GS $\leq 3+4$ at radical prostatectomy, and this number could not be ignored. This result indicates that some patients with biopsy GS $4+4$ or GS $4+3$ are often overestimated. In addition, we showed that the predictor of downgrading was lower percentage of highest GS cores out of positive biopsy cores.

There are few reports of downgrading from biopsy GS to prostatectomy GS, all of which focused on patients with biopsy GS 4+4 (9-11). Ginsburg et al reported that 59\% were downgraded to GS $\leq 7$ at prostatectomy, and $\leq 2$ biopsy cores of GS $4+4, \leq 50 \%$ maximal tumor involvement of the cores demonstrating GS 4+4, and the presence of GP 3 in separate biopsy cores was associated with downgrading, from 
Table I. Patient baseline demographics and pathological outcomes.

\begin{tabular}{|c|c|}
\hline Variable & Value \\
\hline Median age, years (IQR) & $69(64.5-72.0)$ \\
\hline Median PSA level at diagnosis, ng/ml (IQR) & $6.3(4.93-8.64)$ \\
\hline Median PSA density, ng/ml/cc (IQR) & $0.25(0.17-0.38$ \\
\hline Median prostate volume, cc (IQR) & $27(20.5-31.9)$ \\
\hline Number of biopsy cores, $\mathrm{n}(\mathrm{IQR})$ & $12(12-14)$ \\
\hline Number of positive biopsy cores, n (IQR) & $3(2-5)$ \\
\hline Percent of positive cores out of all biopsy cores, median \% (IQR) & $25(15.0-36.6)$ \\
\hline Percent of highest Gleason score cores out of positive biopsy cores, median \% (IQR) & $30(10.0-47.5)$ \\
\hline $\begin{array}{l}\text { Maximum percent of cancer involvement within a positive core with highest Gleason scores, } \\
\text { median \% (IQR) }\end{array}$ & $50(33.3-100.0)$ \\
\hline \multicolumn{2}{|l|}{ Biopsy Gleason score, n (\%) } \\
\hline $4+3$ & $52(50.5)$ \\
\hline $4+4$ & $51(49.5)$ \\
\hline \multicolumn{2}{|l|}{ Clinical stage, n (\%) } \\
\hline $\mathrm{T} 1 \mathrm{c}$ & $13(12.6)$ \\
\hline $\mathrm{T} 2 \mathrm{a}$ & $79(76.7)$ \\
\hline $\mathrm{T} 2 \mathrm{~b}$ & $6(5.8)$ \\
\hline $\mathrm{T} 2 \mathrm{c}$ & $5(4.9)$ \\
\hline Median follow-up, months (IQR) & $36(12.0-54.5)$ \\
\hline
\end{tabular}

Table II. Radical prostatectomy Gleason score stratified by biopsy Gleason score.

\begin{tabular}{|c|c|c|c|c|c|c|c|c|c|c|c|}
\hline \multirow{2}{*}{$\begin{array}{l}\text { Biopsy Gleason } \\
\text { score }\end{array}$} & \multicolumn{11}{|c|}{ Radical prostatectomy Gleason Score, n (\%) } \\
\hline & HGPIN & $3+3$ & $3+4$ & $3+4+\mathrm{T}$ & $4+3$ & $4+3+\mathrm{T}$ & $3+5$ & $4+4$ & $4+4+\mathrm{T}$ & $9-10$ & Total \\
\hline $4+3$ & $0(0.0)$ & $1(1.9)$ & $26(50.0)$ & $1(1.9)$ & $14(27.0)$ & $6(11.5)$ & $0(0)$ & $4(7.7)$ & $0(0.0)$ & $0(0.0)$ & 52 \\
\hline $4+4$ & $1(2.0)$ & $0(0)$ & $13(25.5)$ & $1(2.0)$ & $17(33.3)$ & $7(13.7)$ & $0(0)$ & $7(13.7)$ & $2(3.9)$ & $3(5.9)$ & 51 \\
\hline
\end{tabular}

T, tertiary pattern 5; HGPIN, high-grade prostatic intraepithelial neoplasia.

a retrospective review of biopsy GS 4+4 (9). Gansler et al also reported that $60 \%$ of biopsy GS 8 were downgraded to $\mathrm{GS} \leq 7$ at prostatectomy, and downgrading was associated with decreasing age, African American race, lower clinical $\mathrm{T}$ stage, lower PSA level, and the combination of primary and secondary GS $(3+5$ greater than $4+4$ greater than $5+3)(10)$. Qi et al reported that $61.5 \%$ of biopsy GS 8 were downgraded on prostatectomy, and the predictive factors of downgrading were lower PSA level at biopsy, number of GS 8 biopsy cores, and the presence of GP 3 on biopsy cores (11). With regard to biopsy GS 8, a large discrepancy between biopsy GS and prostatectomy GS was observed.

The novelty of our study was that we included an analysis of downgrading in biopsy GS $4+3$ patients and defined 'downgrade' as 'to GS $\leq 3+4$ at prostatectomy'. We changed the subject and the definition of downgrading from previous reports because GS $4+3$ and GS $4+4$ had a similar oncological prognosis (1), and $\mathrm{GS} \geq 4+3$ had a significantly poorer prognosis compared to GS 3+4 (2-3). In our study, the incidence of downgrading from biopsy to prostatectomy was $41 \%$. Additionally, we showed that a lower percentage of highest GS cores out of positive biopsy cores was associated with downgrading in prostatectomy specimens. This result of the downgrade factor is easy to understand because it almost matches what we believe to be the case in our clinical practice. Our results support the possibility of oversampling small lesions of GP 4 cancer. Because of the diagnosis of its small lesions, GP 4 may be missed by pathological examination of the prostatectomy specimens, or may be accidentally sampled in the biopsy. The overestimation of risk stratification may sometimes lead to overtreatment. High-risk prostate cancers are aggressively treated. In radiation therapy for prostate cancer, the duration of androgen deprivation therapy at high risk is longer than that at other risk $(12,13)$. The longer term of androgen deprivation therapy is attributable to osteoporosis, metabolic syndrome, diabetes mellitus, cardiovascular events, and a decline in quality of life (14). In addition, downgrading to GS $3+4$ or lower means that active surveillance, a strategy to avoid overtreatment, may be a potential option in some cases (15). In other words, identifying the factors to downgrade prior to 
Table III. Association of characteristics downgraded from biopsy Gleason score $4+4$ or $4+3$ to $\leq 3+4$ at radical prostatectomy.

\begin{tabular}{|c|c|c|c|}
\hline Variable & Downgrade & No downgrade & P-value \\
\hline Patients, $\mathrm{n}$ & 42 & 61 & \\
\hline Median age, year (IQR) & $69.5(65-72)$ & $69(63-72)$ & 0.965 \\
\hline Median PSA level at diagnosis, ng/ml (IQR) & $6.4(5.00-8.07)$ & $6.23(4.89-8.90)$ & 0.973 \\
\hline Median PSA density, ng/ml/cc (IQR) & $0.23(0.16-0.35)$ & $0.26(0.18-0.39)$ & 0.409 \\
\hline Median prostate volume, cc (IQR) & $28(21.0-31.3)$ & $26(20-32)$ & 0.552 \\
\hline Number of biopsy cores, $\mathrm{n}$ (IQR) & $12(12-14)$ & $12(12-14)$ & 0.442 \\
\hline Percent of positive cores out of all biopsy cores, \% (IQR) & $25(16.7-35.1)$ & $25(15.0-37.5)$ & 0.939 \\
\hline Percent of highest Gleason score cores out of positive biopsy cores, \% (IQR) & $45(30.8-66.7)$ & $66.7(40-100)$ & 0.025 \\
\hline$\leq 55, \mathrm{n}(\%)$ & $30(71.4)$ & $29(47.5)$ & \\
\hline$>55, \mathrm{n}(\%)$ & $12(28.6)$ & $32(52.5)$ & \\
\hline Maximum percent of cancer involvement within a positive core with highest & $20(10.0-37.5)$ & $30(20-50)$ & 0.048 \\
\hline \multicolumn{4}{|l|}{ Gleason scores, \% (IQR) } \\
\hline$\leq 27.5, \mathrm{n}(\%)$ & $25(59.5)$ & $24(39.3)$ & \\
\hline$>27.5, \mathrm{n}(\%)$ & $17(40.5)$ & $37(60.7)$ & \\
\hline Clinical T stage, $\mathrm{n}(\%)$ & & & 0.361 \\
\hline T1c & $7(16.7)$ & $6(9.8)$ & \\
\hline $\mathrm{T} 2 \mathrm{a}$ & $31(73.8)$ & $48(78.7)$ & \\
\hline $\mathrm{T} 2 \mathrm{~b}$ & $1(2.4)$ & $5(8.2)$ & \\
\hline $\mathrm{T} 2 \mathrm{c}$ & $3(7.1)$ & $2(3.3)$ & \\
\hline
\end{tabular}

Table IV. Multivariate models for the prediction of Gleason score downgrading after radical prostatectomy in patients with biopsy a Gleason score of $4+3$ and $4+4$.

\begin{tabular}{|c|c|c|c|}
\hline \multirow[b]{2}{*}{ Variable } & \multicolumn{3}{|c|}{ Multivariate } \\
\hline & OR & $95 \% \mathrm{CI}$ & P-value \\
\hline Age at diagnosis & 0.989 & $(0.915-1.069)$ & 0.786 \\
\hline PSA level & 0.990 & $(0.869-1.127)$ & 0.880 \\
\hline Percent of highest Gleason score cores out of positive biopsy cores $\leq 55 \%$ & 2.469 & $(1.029-5.925)$ & 0.043 \\
\hline $\begin{array}{l}\text { Maximum percent of cancer involvement within a positive core with highest } \\
\text { Gleason scores } \leq 27.5 \%\end{array}$ & 1.786 & $(0.740-4.309)$ & 0.197 \\
\hline \multicolumn{4}{|l|}{ Clinical T stage: T1c (reference) } \\
\hline $\mathrm{T} 2 \mathrm{a}$ & 0.599 & $(0.169-2.131)$ & 0.429 \\
\hline $\mathrm{T} 2 \mathrm{~b}$ & 0.196 & $(0.016-2.397)$ & 0.202 \\
\hline $\mathrm{T} 2 \mathrm{c}$ & 1.055 & $(0.111-10.012)$ & 0.963 \\
\hline
\end{tabular}

treatment could contribute to a wider range for less invasive treatment options. Furthermore, our findings of the prediction of downgrading from biopsy to prostatectomy specimens have important implications for providing treatment while ensuring safety. Patients with downgrading may have a more favorable prognosis after prostatectomy than expected by biopsy GS.

Previous studies have reported discrepancies between prostate biopsy specimens and prostatectomy specimens $(4,5)$. We presume the discrepancy between biopsy and prostatectomy GS is largely due to the difference in diagnostic procedures. In biopsy pathology, the highest biopsy GS is used to avoid underestimation. Currently, pre-biopsy magnetic resonance imaging (MRI) has shown promise in the detection and characterization of prostate cancer (16). In this context, MRI could contribute to filling this diagnostic gap. Regarding the upgrading from biopsy to prostatectomy specimens, Alqahtani et al evaluated whether MRI has the potential to narrow the discrepancy of histopathological grades between biopsy and radical prostatectomy, using the data of 102 patients with localized prostate cancer at a single institution (17). The report showed that the PIRADS v2.0 score was associated with postoperative GS upgrading and created a nomogram for GS upgrading prediction. However, prostate cancer is a popular disease and may be diagnosed at any institution, although not all institutions have MRI. In this respect, our results may help fill this diagnostic gap. 
This study has several limitations. First, this study was a retrospective analysis at a single institution, so the number of patients was limited. Second, most patients presented with biopsies performed at an outside institution. Therefore, the biopsy indication and biopsy technique varied. However, all biopsy specimens were reviewed at our institution before RALP. Finally, diagnostic PSA level $\geq 20 \mathrm{ng} / \mathrm{ml}$ and clinical $\mathrm{T}$ stage $\geq \mathrm{cT} 3$ were excluded from the inclusion criteria because these are high-risk parameters if there is a GS downgrade from biopsy to prostatectomy specimens. Despite these limitations, we believe that our study findings are meaningful for providers in real-world clinical practice in the context of patients' treatment decision-making and counseling.

In conclusion, we highlighted that patients with biopsy GS $4+4$ or GS $4+3$ often have a downgrade to GS $3+4$ or less in prostatectomy specimens. The lower percentage of highest GS cores out of positive biopsy cores was associated with downgrade. Our study findings have important implications for providing treatment with a safer guarantee than the risk expected by biopsy GS.

\section{Acknowledgements}

Not applicable.

\section{Funding}

No funding was received.

\section{Availability of data and materials}

The datasets used and/or analyzed are available from the corresponding author on reasonable request.

\section{Authors' contributions}

YT conceived and designed the present study, analyzed and interpreted the data, and drafted the manuscript. KF, SH, IM, AI, MY, YMi, YMa, TK, RT, HT, NU and MS reviewed and collected data. All authors have read and approved the final version of the manuscript.

\section{Ethics approval and consent to participate}

The current study was approved by the Institutional Review Board of Kagawa University (admission no. 2020-074). The need for informed consent was waived given the retrospective nature of the study, but study information was disclosed on the website and opportunities for refusal were guaranteed.

\section{Patient consent for publication}

Not applicable.

\section{Competing interests}

The authors declare that they have no competing interests.

\section{References}

1. Pierorazio PM, Walsh PC, Partin AW and Epstein JI: Prognostic Gleason grade grouping: Data based on the modified Gleason scoring system. BJU Int 111: 753-760, 2013.

2. Chan TY, Partin AW, Walsh PC and Epstein JI: Prognostic significance of Gleason score 3+4 versus Gleason score 4+3 tumor at radical prostatectomy. Urology 56: 823-827, 2000.

3. National Comprehensive Cancer Network. Clinical practice guidelines in oncology prostate cancer version 1.2020, 2020.

4. Epstein JI, Feng Z, Trock BJ and Pierorazio PM: Upgrading and downgrading of prostate cancer from biopsy to radical prostatectomy: Incidence and predictive factors using the modified Gleason grading system and factoring in tertiary grades. Eur Urol 61: 1019-1024, 2012.

5. Fine SW and Epstein JI: A contemporary study correlating prostate needle biopsy and radical prostatectomy Gleason score. J Urol 179: 1335-1338, 2008.

6. Budäus L, Graefen M, Salomon G, Isbarn H, Lughezzani G, Sun M, Chun FK, Schlomm T, Steuber T, Haese A, et al: The novel nomogram of Gleason sum upgrade: Possible application for the eligible criteria of low dose rate brachytherapy. Int J Urol 17: 862-868, 2010.

7. Hong SK, Han BK, Lee ST, Kim SS, Min, KE, Jeong SJ, Jeong H, Byun SS, Lee HJ, Choe G and Lee SE: Prediction of Gleason score upgrading in low-risk prostate cancers diagnosed via multi ( $>$ or=12)-core prostate biopsy. World J Urol 27: 271-276, 2009.

8. Colleselli D, Pelzer AE, Steiner E, Ongarello S, Schaefer G, Bartsch G and Schwentner C: Upgrading of Gleason score 6 prostate cancers on biopsy after prostatectomy in the low and intermediate tPSA range. Prostate Cancer Prostatic Dis 13: 182-185, 2010.

9. Ginsburg K, Cole AI, Silverman ME, Livingstone J, Smith DW, Heilbrun LK, Shi D, Mehra R, Sakr WA, Morgan TM and Cher ML: Should all prostate needle biopsy Gleason score $4+$ $4=8$ prostate cancers be high risk? Implications for shared decision-making and patient counselling. Urol Oncol 38: 78.e1-78. e6, 2020.

10. Gansler T, Fedewa S, Qi R, Lin CC, Jemal A and Moul JW: Most Gleason 8 biopsies are downgraded at prostatectomy-does $4+$ 4=7? J Urol 199: 706-712, 2018.

11. Qi R, Foo WC, Ferrandino MN, Davis LG, Sekar S, Longo TA, Jibara G, Han T, Gokhan I and Moul JW: Over half of contemporary clinical Gleason 8 on prostate biopsy are downgraded at radical prostatectomy. Can J Urol 24: 8982-8989, 2017.

12. Mottet N, Bellmunt J, Bolla M, Briers E, Cumberbatch MG, De Santis M, Fossati N, Gross T, Henry AM, Joniau S, et al: EAU-ESTRO-SIOG guidelines on prostate cancer. Part 1: Screening, diagnosis, and local treatment with curative Intent. Eur Urol 71: 618-629, 2017.

13. Sanda MG, Cadeddu JA, Kirkby E, Chen RC, Crispino T, Fontanarosa J, Freedland SJ, Greene K, Klotz LH, Makarov DV, et al: Clinically localized prostate cancer: AUA/ASTRO/SUO guideline. Part II: Recommended approaches and details of specific care options. J Urol 199: 990-997, 2018.

14. Alibhai SM, Breunis H, Timilshina N, Naglie G, Tannock I, Krahn M, Warde P, Fleshner NE, Canning SD and Tomlinson G: Long-term impact of androgen-deprivation therapy on physical function and quality of life. Cancer 121: 2350-2357, 2015.

15. Raldow AC, Zhang D, Chen MH, Braccioforte MH, Moran BJ and D'Amico AV: Risk group and death from prostate cancer: Implications for active surveillance in men with favorable intermediate-risk prostate cancer. JAMA Oncol 1: 334-340, 2015.

16. Ahmed HU, El-Shater Bosaily A, Brown LC, Gabe R, Kaplan R, Parmar MK, Collaco-Moraes Y, Ward K, Hindley RG, Freeman A, et al: Diagnostic accuracy of multi-parametric MRI and TRUS biopsy in prostate cancer (PROMIS): A paired validating confirmatory study. Lancet 389: 815-822, 2017.

17. Alqahtani S, Wei C, Zhang Y, Szewczyk-Bieda M, Wilson J, Huang Z and Nabi G: Prediction of prostate cancer Gleason score upgrading from biopsy to radical prostatectomy using pre-biopsy multiparametric MRI PIRADS scoring system. Sci Rep 10: 7722,2020 . 